\title{
Conflict of Interest Policies Can Stifle Students and Innovation
}

\section{Liz Christenbury (Deloitte)}

KEYWORDS: Information, Software, Data, Entrepreneurship, Innovation, Research Methods, Product Development, Technology Commercialization.

In the private sector, collaboration between the people who develop and commercialize new technologies is essential to a successful new venture. But in the college setting, Conflict of Interest policies often stand in the way because they can prevent students from being involved in both the startup activities and research for the same underlying technology. While these policies are necessary, should be adjusted to encourage innovation and better learning for students.

I saw this myself as a graduate student conducting research under a National Science Foundation Accelerating Innovation Research - Technology Translation grant. My university's COI policy prevented me from participating in the efforts to get a promising new product to market because I had also been involved in researching the best product features. I hit this COI roadblock when I followed the Lean Startup Methodology, an iterative, customer-centric process that helps entrepreneurs quickly find product-market fit.

\section{Background}

As an MBA graduate student working under the AIR-TT grant, I was responsible for conducting primary market research through customer interviews, identifying the feasibility of a technology as a commercial product, and developing an appropriate market entry strategy. However, the University of Wisconsin's Conflict of Interest (COI) policy directly affected the scope of activities I was permitted to conduct when the principal investigator's startup began selling the technology. The COI policy created an environment where I was not able to both conduct research as part of the AIR-TT grant and participate in the business entity, which was directly testing the product with customers. This condition hindered my ability to leverage the network and operations of the business entity in order to follow the
Lean Startup Methodology in sufficiently executing the duties of the commercialization research grant.

\section{AIR-TT Grant}

The National Science Foundation (NSF) describes the AIR-TT grant as a mechanism that provides the research team with an opportunity to "[advance] their understanding of business as it relates to their technology, and...learn about innovation and technology translation." Dr. Krishnan Suresh, professor in the School of Engineering at UW-Madison and principal investigator on the grant, pursued the AIR-TT grant to receive funding to explore the commercialization of a cloud-based version of his engineering design technology, PareTO, which had been developed and widely tested among students and academics since 2008. The grant was accepted in the spring of 2015 , and the team was formed. Professor Suresh sought partnership from the School of Business in order to seek business and entrepreneurship expertise. As the MBA graduate student on the grant team, my role was to follow leading commercialization research practices in order to complete primary market research, and determine the feasibility of the technology and the appropriate market entry strategy. In the context of the AIR-TT grant, my objective while conducting these activities was to understand how to best bring the technology to market. 


\section{Breakthrough Technology}

PareTO computes Finite Element Analysis and Topology Optimization for engineering designs. Finite Element Analysis (FEA) takes inputs from the designer such as dimensions, stress areas, and other properties to analyze weaknesses and effects on the object in relation to those properties. A typical FEA computation then shows a type of heat map on the original object where the engineer can visually see the analysis of the design. Topology Optimization (TO) takes FEA results along with a designer's additional inputs like mass reduction percentage and assembly constraints and produces an optimized design that gives a solution that correctly solves the engineer's problem. The optimized design is generally not something the engineer may have thought of trying, which saves time spent testing iterations of the object. Suresh and his team discovered through testing of well-known, difficult and typically timeconsuming problems that their technology processed solutions faster, more reliably and cheaper than the competition.

Using existing technology, many of the common engineering problems take hours to solve, some even days depending on the complexity of what's being calculated. PareTO found a way to produce solutions in a matter of seconds or minutes and experienced failures in a fraction of the time compared to other systems. As an MBA student, I knew that these were several valuable differentiating factors about this software and was eager to begin research.

\section{Lean Methodology Research Framework}

Traditional New Product Development (NPD) consists of ideation, creation, and perfection of a product without considering customer input and feedback until the product is put on the market. It's enormously risky for entrepreneurs because success is highly uncertain. The Lean Startup Methodology, on the other hand, involves customer input very early on, and strives to create a product that solves a clear and known problem. Entrepreneurs use customer feedback to produce a Minimum Viable Product (MVP) that meets the most pressing customer need. Once the MVP is developed, the entrepreneur follows a "learn, build, measure" process to continuously improve and build upon the MVP. In this fashion, the business grows organically around the customer and gains focus on where the product fits within the market.

In alignment with the AIR-TT grant, the research team sought to develop an MVP that met customer needs as a result of the business research findings. In order to shape the development of the MVP, I followed the Lean Startup Methodology framework in conducting the business research activities. Following Lean allowed for iteration and adjustment of the product quickly which would directly influence the eventual business model.

The cloud-based version of PareTO, CloudTopOpt, had been available for user testing online for several years. In order to test our hypothesis that CloudTopOpt met users' design optimization needs and would create value for a business, I conducted market research by collecting feedback from users of CloudTopOpt. Users provided information regarding user experience, complaints and improvement requests along with miscellaneous personal preferences. I also conducted market and industry research to understand the industry structure and trends to compare with the PareTO technology.

The insights from customer interviews and industry reports led our team to recommend that Suresh first release PareTO's desktop plug-in version, PareTOWorks, instead of CloudTopOpt, as I learned that users were conditioned to using desktop platforms for design engineering software as part of their day-today work and sought products that integrated with the system with which they were familiar. In order to test how customers would respond to an offering of the desktop version of PareTO, we conducted further research via the 2016 SOLIDWORKS World conference in Dallas, TX. At the conference, we conducted pricing tests, interviewed users who fit our 
customer profile, and learned about competing products.

It is important to note that industry and market research showed that entering the space of design optimization software would be challenging. Big players offered existing solutions; development resources were abundant; acquisitions were frequent. With this information, Prof. Suresh decided to proceed with technology transfer procedures in order to begin commercializing the PareTOWorks product. However, when PareTOWorks launched as a commercial product, my activities following the lean startup methodology as part of the grant became limited due to Conflict of Interest policies.

\section{Conflict of Interest}

Federal and state laws and regulations place specific Conflict of Interest (COI) management requirements on Universities. As a result, public universities take $\mathrm{COI}$ very seriously. At most universities the professor's involvement with outside companies is closely managed by a COI process. Professors are currently permitted to conduct research on a topic and be involved in a startup company that uses that same research as long as conflicts that might arise from the activity are appropriately mitigated and managed by all parties involved. Moreover, successful technologies generally depend on the involvement of the original inventors. However, students are not permitted to simultaneously work under the same professor at a university and at a company. The concern is that it creates an opportunity for abuse of the student's time and effort. For example, a professor might delay a students' ability to complete their degree because they did not complete specific work for a professor's outside company at which they were also employed. While COI is an important policy that can prevent abuse, prohibiting students from simultaneously working for a professor's lab at the university and the professor's respective company has three negative consequences. First, this policy can impede effective and efficient commercialization of the technology; second, it can create barriers to career opportunities for the student; and third, it can reduce potential student learning as a result of being involved in the project.

In terms of impeding commercialization of the technology, the $\mathrm{COI}$ policy created an information barrier between the startup company and the grant team. The barrier prevented me from receiving and using information regarding sales and user feedback of the PareTOWorks product. It is important to clarify the subtle, but crucial, limitation this created for us. While the grant explored the commercial viability of the cloudbased PareTO technology, Lean Startup Methodology demanded that we seek the answer to a more implicit question: "Is the cloud implementation an appropriate platform for this technology? Is this what engineers truly want and need?" Translated into a hypothesis to test: "Engineers want to perform design optimization on the cloud." However, the fact that the desktop product was selling and making money prevented me from fully testing this hypothesis. While Suresh and the team at his startup were privy to the information around the sale of PareTOWorks, we as a grant team could not use this information to apply the lean startup methodology comprehensively. To successfully use lean startup methodology, one must have access to customer information and user feedback from an iteration of the product being sold. One must also be able to test pricing hypotheses and be involved in the customer acquisition activities in order to estimate value of the product and which format it should take. This limitation likely slowed the technology commercialization process and prevented effective information flow between customers and our grant team.

The COI policy also can create barriers in terms of career development. For example, if I had been a part of the startup company in addition to working on the grant team, I would have had the opportunity to experience a role within a startup company, specifically within an industry that I had learned much about over the past year. For someone completing a business degree and interest in learning more about application of entrepreneurship theory in startups, the ability to contribute to a startup with little to no financial risk themselves is very attractive. This experience might have positioned me to help commercialize other University technologies in the future. Unfortunately, students with similar situations and interests are at a disadvantage in terms of career exploration and development due to the COI policy because they cannot take advantage of all opportunities. 
Lastly, the policy can reduce students' potential personal learning. While the business development theories that I learned in my entrepreneurship and operations courses were valuable and prepared me for my career, it would have been useful to supplement my education with hands-on learning. Specifically, if I had been able to participate in both the grant and the startup business, I could have learned first-hand what goes into forming a startup, putting a team together, and operating a business in technology. Furthermore, I could have learned the effects of research findings on a business' operations, and how the knowledge from the business outcomes feeds back into research efforts. Finally, I could have witnessed the iterative product development process that produces the business' MVP, which would have given much insight into further research efforts of competing products in the market in terms of R\&D investment, lead times, and customer satisfaction.

\section{Opportunity for Improvement}

The opportunity that presents itself from this issue would be a collaborative initiative between the functions involved in the lifecycle of the grant: funding, formation, execution and oversight. Specifically, we see a gap in communication, feedback and knowledge between the individuals who execute the grant and the organizations who fund and oversee the grant. Those who execute the grant have knowledge of business theory and development, but these methods of execution are not reflected in the policies that guide research activity or in the federal programs that provide the funding.

In order to close the gap between these functions, my recommendation would be for all parties to form a collaborative funding program to both explore the opportunity for technology transfer and also test the MVP in the market via a startup entity while using proven business development methods (e.g. Lean). Compared to the AIR-TT grant, this new program would proactively create an environment that fosters entrepreneurship and is guided by unique COI policy that does not create barriers for student knowledge and development. With a new type of funding program and policies governing it, students can be utilized effectively as part of the research team and be able to explore career opportunities and increase personal knowledge during the research term.

\section{Conclusion}

The Lean Startup Methodology is a state of the art approach that is used to reduce the risks of commercializing novel technologies. The limitation that the grant team faced was due to a combination of university COI policies while following the Lean Startup Methodology under the NSF AIR-TT grant. The COI policies are created in order to adhere to federal and state legislature and protect student researchers and professors. Without these policies, it is likely that undesirable situations may occur between students and professors. However, we believe that our case is not a unique one. There is a need for collaboration between universities, researchers, and federal institutions such as the NSF to find solutions to this type of limitation.

Progress has already been made in cases such as the NSF I-CORPS program, a grant provided for researchers interested in following the Lean Startup Methodology in bringing technology to market. However, the I-CORPS program focuses on researchers that have not yet created a startup company. I agree with Callier et. al. in that programs such as these "could be augmented with training to help early career scientists develop the necessary expertise in entrepreneurship and commercialization." ${ }^{2}$ A new funding program that fosters entrepreneurship during the transfer of technology would prevent students from encountering issues like my own and offer opportunities to develop skills in entrepreneurship and commercialization. 


\section{Acknowledgements}

I would like to thank Professor Krishnan Suresh of the School of Engineering at the University of WisconsinMadison. Without your breakthrough technology, I would not have had the opportunity to participate in my research. Thanks go to Professor Jon Eckhardt of the Wisconsin School of Business and the Weinert Center for Entrepreneurship for his guidance and review during my research and work on this editorial. Thanks also go to Amir Mirzendehdel for his guidance on the PareTO technology and general understanding of the engineering software industry. Thanks to the Wisconsin Alumni Research Foundation for their time taken in sharing how technology is transferred at UW-Madison.

\section{References}

1 "Partnerships for Innovation: Accelerating Innovation Research - Technology Transfer". National Science Foundation. https://www.nsf.gov/eng/iip/pfi/air-tt.jsp.

2 Callier, Viviane, Steve Greenbaum, and Nathan L. Vanderford. 2015. "The Traditional Training of PhDs

Threatens the Technology Transfer and Entrepreneurship Pipeline While Innovative Programs Provide Unique Recovery Opportunities." Technology Transfer and Entrepreneurship 2 (1): 51-58. 